\title{
Digital distribution of academic journals and its impact on scholarly communication: Looking back after 20 years
}

\section{David J Solomon, PhD \\ College of Human Medicine \\ Michigan State University}

\begin{abstract}
It has been approximately 20 years since distributing scholarly journals digitally became feasible. This article discusses the broad implications of the transition to digital distributed scholarship from a historical perspective and focuses on the development of open access (OA) and the various models for funding $O A$ in the context of the roles scholarly journals play in scientific communities.
\end{abstract}

\section{Introduction}

The technological innovations that made digitally distributed journals feasible coalescing about 20 years ago have profoundly changed scholarly publication. One of the most important changes, though far from the only one, has been open access (OA) publishing, making the content of scholarly journals freely available and funding the cost of publication via means other than subscription fees. A lively debate has gone on for years as to whether OA should be the dominant economic model for distributing scholarly journals and, if so, how it might be funded. To some extent, this debate has obscured the broad implications of digitally distributing scholarly journals. This article attempts to put OA in perspective as one piece of a far more profound evolution that has impacted on virtually every aspect of scholarly publishing. ${ }^{1}$

As it became clear that scholarly journals were going to be distributed digitally, Ann Schaffner argued that in order to understand how a digital system might develop, it would be helpful to start by looking for clues in how scholarly journals developed in paper format. ${ }^{2}$ Shaffner also argued there was a need to consider the various roles that these journals have played in scientific communities and how these roles might impact the development of a new digital distribution system. She identified five unique roles, listed in the order of importance: building a collective knowledge base; communicating information; validating the quality of research; distributing rewards; and building scientific communities.

\section{A brief history of scholarly journals}

Schaffner noted that the technology that made scientific journals possible, the printing press and a viable postal service in Europe, developed well before the launch of Philosophical Transactions of the Royal Society in 1665, generally considered the first scientific journal. The key ingredient that precipitated scholarly journals was not technology but science itself. As the scientific method began to take hold. the "natural philosophers," as they were called at the time, began shifting their focus from interpreting and debating the classics to observation and experimentation. This change in focus made it 
necessary to disseminate the results of small discreet studies and observations. This was done via letters that were often copied and further disseminated through scientific societies, which began forming during the beginning of the $17^{\text {th }}$ century. Henry Oldenburg, the secretary of the Royal Society, was heavily involved in this re-dissemination and Philosophical Transactions (Phil Trans for short), may have been conceived in part due to his frustration with the highly inefficient system of hand-copying to further disseminate these letters.

John Willinsky notes that Phil Trans fit in a niche between books, the traditional means of scholarly dissemination, and the letters which had grown in importance for presenting the results of small focused studies during this period. ${ }^{3}$ Letters provided a flexible and interactive mode of communication albeit a highly inefficient one. Books could not fulfill the need to disseminate small discrete studies but provided a more comprehensive and permanent means of presenting theories along with summarizing and interpreting findings. Journals sat somewhere in the middle, providing an efficient means of communicating discrete studies and observations but less interactive and less timely than letters. Over time, Oldenburg's idea caught on and journals became the main vehicle for disseminating new scientific knowledge in most fields.

The development of journals such as Phil Trans also solved another important problem brought about by the inefficient system of informal letters. They clarified the origin of a research finding or idea, giving appropriate credit to the natural philosopher who actually made the discovery. According to Guédon, this was a huge issue and prior to the development of scientific journals, natural philosophers often refrained from sharing their observations and discoveries for fear of others claiming credit for their ideas. $^{4}$ Interestingly, it took quite a while before there was a realization that scholarly journals were forming a comprehensive archive of knowledge, what this author believes most people would agree is the most important function that they serve today. Although books also served this purpose, journals turned out to be much better suited for chronicling the results of individual studies that had become the life blood of science.

Systems for validating scholarly manuscripts and the research results that they contained also evolved slowly and haphazardly and were implemented perhaps more to protect the good name of the learned society that sponsored the journal than anything else., ${ }^{5,}$ Phil Trans was eventually peer-reviewed and is sometimes given credit as the first peer-reviewed journal though similar systems evolved somewhat earlier. ${ }^{5}$ It took until 1752, nearly a century after Phil Trans was first published, for it to become peerreviewed.

The format of scientific journals has evolved slowly over several hundred years. The structure of articles, referencing systems and abstracts have all gradually developed into a very efficient and effective system for disseminating scientific information and allowing scholars ${ }^{7}$ to quickly find the relevant literature and within an article, the specific details that they needed. ${ }^{2}$ Disciplines began to develop their own formats that best suited the nature of the scholarship conducted. The sciences and social sciences, where discreet observation and experimentation is widely used, gravitated towards the use of journals while the humanities, which tend to have a broader, more integrated approach to their 
scholarship, inclined more towards monographs. In addition, a whole set of norms and conventions developed that have allowed journals to operate effectively. For example, peer-review is expected to be confidential until a manuscript is published and authors are expected to refrain from submitting the same manuscript to more than one journal at the same time.

Journals have traditionally been closely tied to scholarly organizations such as the Royal Society. They largely arose out of these societies and remained closely linked to these societies up until the later part of the $20^{\text {th }}$ century. Again, the road was a bit rocky. For example, Phil Trans shut down for five years after Oldenburg's death as operating the journal was largely his own personal project rather than part of the Royal Society. The Royal Society also did not take full fiscal responsibility for the journal until 1752 , which is when they also implemented peer-review. ${ }^{6}$

Journals were largely owned by these societies and were operated at a significant cost. They had small circulations outside of societal membership and were expensive to publish. Library budgets for journals were limited. Societies maintained their journals through subsidies and page charges to the authors since these journals were seen as valuable by the societies. This began to change in the latter half of the 20th century as governments in the industrialized world began investing heavily in research, largely through grants to their university systems and focusing in the scientific, technical and medical (STM) areas. The investment paid off and scientific research grew rapidly. Not only did the number of manuscripts needing to be published grow, but the research spawned whole new specializations such as molecular biology, requiring more and more specialized journals. At the same time, academic libraries and their budgets expanded with the influx of funding to the universities for research, allowing them, at least initially, to cover the increased costs of expanding their journal portfolios.

Commercial publishers, who prior to this time published few scholarly journals, began taking over journals from societies and launching their own journals with the help of individual scientists or scholars as editors and editorial board members. Initially, this was a real service, filling a void in light of the rapidly increasing need to publish more articles in existing journals to publish and for the creation of more specialized journals. Publishers found owning scholarly journals were not only profitable but, in fact, could be extremely lucrative. During the last 25 years of the $20^{\text {th }}$ century, there was a rapid expansion of publisher-owned journals in conjunction with a consolidation of scholarly publishing as the larger publishing houses, seeing a highly productive market, began buying up smaller ones. This continued alongside an increase in subscription fees that, with a few notable exceptions, has far exceeded the subscription fees of society-owned journals in similar fields. ${ }^{8}$ The increase in subscription prices is complex. In part, as publishers have claimed, publishing more and more journals in highly specialized fields is expensive but, clearly, this is not the only reason. Scholarly publishing, which was a money losing proposition prior to the second half of the twentieth century, became very profitable and the pricing of some journals has become, by almost any standard, exorbitant. By 2006, approximately $45 \%$ of scholarly journals were owned by commercial publishers with another $17 \%$ published by them under contract. ${ }^{9}$ The change is more dramatic in the STM fields where commercial publishing is concentrated in a few publishers and is extremely profitable. 
The rapid post-World War II expansion of STM research was characterized by the ensuing commercialization of scholarly publishing and an increase in subscription fees, far exceeding library acquisition budgets. This has resulted in a funding crisis that has strained the symbiotic relationship among publishers, academic libraries and scholars. In this environment of rising tensions, with the evolution of digital networks about 1993, it became technically feasible to move from a paper to a digital distribution system for scholarly journals.

In summary, scholarly journals evolved slowly, gradually filling the roles that they currently serve in scientific and scholarly communities. The formats and conventions that allow the peer-review and publication to work effectively also evolved slowly, most likely through trial and error. The technology that made journals possible, the printing press and a viable postal system, were essential but only one of many factors that were responsible for development of scholarly journals. Journals were closely tied to scholarly societies with varying missions until a rapid expansion of scientific research spawned an increasing number of journals owned and operated by commercial publishers. Social and economic forces as well as the evolving nature of science itself were the real drivers of the evolution of scholarly journals; the format and processes of scholarly publishing took several centuries to develop to its current state.

\section{Transitioning to a digital distribution system}

With paper distribution, there was a symbiotic relationship among publishers, librarians and scholars. Scholars produced the manuscripts, publishers managed the peer-review process and took the raw material through the publication and distribution process with libraries purchasing and archiving the material as well as facilitating scholars' access to the material in a variety of ways. The system worked reasonably well until, as noted, the tensions among the three partners increased when the pricing of serials grew dramatically in the late $20^{\text {th }}$ century. Digital distribution changed the relationship among publishers, libraries and scholars. Many of the most expensive and labor-intensive activities of both publishers and libraries were now done by information technology, leaving it up in the air as to which group would be responsible for the remaining roles and manage the information technology that archived and disseminated these new digitally distributed journals. Furthermore, the processes of scholarly publishing had become so automated and comparatively inexpensive that, at least on a small scale, scholars could publish scholarly journals using their own volunteer labor along with small subsidies.

The initial experiments in digitally distributed journals can be traced at least as far back as $1982^{10}$. However, there were significant barriers that precluded digital dissemination replacing traditional paper publishing. Few scholars were using these new wide area networks in the 1980 s and accessing them required technical skills that most scholars neither had nor wished to develop. Around 1993, with the confluence of access to the Internet, protocols allowing the transmission of formatted text and graphics and easy-to-use browsers, these barriers began to disappear and digitally distributed scholarly journals became a real possibility. ${ }^{11}$ The number of digitally distributed journals grew almost exponentially in the mid-1990s. They, however, were largely experiments created by the academics themselves. A few like 
Gene Glass's superb journal Educational Policy Analysis Archives ${ }^{12}$ quickly gained notoriety as the best journals in their field. By and large, however, these were small experiments conducted by university faculty with no experience in publishing and the quality was marginal at best. Many of these journals were not peer-reviewed and, more often than not, petered out almost as quickly as they appeared. They were also largely dismissed as little more than vanity publishing, without the perceived scholarly rigor of traditionally published journals.

Commercial publishers, after a short period of time, saw the inevitability of digital distribution as well as the monetary potential and invested heavily in developing platforms for distributing electronic versions of the journals that they published directly to the scholars who read them, distributing individual articles rather than the whole issue required with paper distribution. Societies as well as commercial publishers largely retained control over the majority of the journals published both paper and digital versions. With digital distribution, publishers began to subsume the roles of archiving and distributing scholarly journals, long held by libraries. The efficiencies of electronic publishing and the unique characteristics of digital distribution opened up a wide range of possibilities for different types of publishing models. Among them, of course, was the possibility of funding publication via means other than subscription fees.

During this period, a growing number scholars as well as librarians began to see the potential of digital distribution for developing new publishing models. This included the fact that, while publishing took resources, they were largely "first copy" costs and the additional cost of distributing a virtually unlimited number of copies was next to nothing. This made it possible to distribute scholarly journals without charging for access and funding publication by means other than subscription fees. While it took several more years for the open access movement to coalesce, during the mid and late 1990's the concept was gaining support in the academic and library communities, motivated by innovative projects such as Paul Ginsparg's extremely successful preprint server in physics. ${ }^{13}$

In 1999, Harold Varmus, the Director of the National Institutes of Health (NIH) blew the doors off scholarly publishing with a proposal for freely accessible archive of biomedical research reports that, in theory, would largely replace traditional journals as we know them. ${ }^{14}$ The original E-biomed proposal included both a peer-reviewed component, operated by editorial boards in a model similar to traditional peer-reviewed journals, as well as a lightly reviewed archive of manuscripts that would be posted almost immediately after submission. In Vamus's own words:

"The essential feature of the plan is simplified, instantaneous cost-free access by potential readers to E-biomed's entire content in a manner that permits each reader to pursue his or her own interests as productively as possible." ${ }^{15}$

While the term Open Access (OA) had yet to be coined, in a very real sense, it was born with this extraordinary proposal. Though many of the links are broken at the time of this writing, the remnants of the proposal and the heated debate that followed remain on the NIH servers. ${ }^{16}$ The reaction as one might expect was strong and makes for some very interesting reading even today. The commercial 
publishers who were making handsome profits off scholarly publishing and were investing heavily in new digital publishing platforms were obviously aghast but they were not alone. Some of the most influential scientific societies that had struggled to publish their journals in the past had grown used to the profit that they were making from their journals.

Being the Director of the NIH carries a lot of weight but it was no match for blowback from both commercial publishers and major scientific societies. When the smoke cleared, E-biomed had been scaled back drastically to what is currently known as PubMed Central; but the seed of open access had been sown. Varmus left the NIH shortly thereafter, his last act, ironically, to approve a press release for PubMed Central. ${ }^{17}$

At a meeting organized by the Open Society Institute in Budapest in late 2001, a small but influential group of open access proponents developed an initiative, really a manifesto, coining the term "Open Access" and, in the minds of many, launching the open access movement. In this author's view, however, it was Varmus's proposal to create E-Biomed that was the key turning point. Although he was unsuccessful in implementing many of the provisions of the proposal, the weight of the head of the largest biomedical funding agency in the world legitimized the concept and initiated the fierce debate that ensued, bringing it to the attention of a far wider group of scholars. Since Varmus's proposal, OA has evolved along three general paths.

\section{Professional Open Access Publishing}

Vitek Tracz is a brilliant scientific publisher who developed a series of innovative products for organizing scientific information, creating companies to market them and later selling the companies to various publishing houses. During the mid-1990's, he became convinced that scholarly publishing was going to move to some form of OA model. As a business man who was extremely adept at turning novel ideas into profitable businesses, Tracz looked at OA publishing not only as an idealistic calling but also as an opportunity to turn a profit by doing something sensible that was probably going to happen one way or another. Tracz formed BioMed Central, (BMC) hiring Jan Velterop, a well-known and respected science publisher, to run the company. ${ }^{18,19}$ The challenge, of course, was not how to publish OA journals, but how to fund them. Tracz came up with the idea of flipping the traditional subscription model, similar to the traditional society model, and having authors rather than readers fund publication. He chose to do it through Article Processing Charges (APCs), a model where authors paid for articles that were published in a journal. Page charges were common in the past and still used by some journals so the concept was not all that radical. With most biomedical research funded through grants, it would not really be the researchers but rather their funders or perhaps their institutions that would pay the APCs. BMC published its first article in July 2000, launching a new era in OA publishing. BMC started with a couple of broad-based high-end journals as well as dozens of journals that had narrow largely discipline-based scopes similar to most traditional journals and were less rigorously peer-reviewed than the flagship journals BMC Medicine and BMC Biology. BMC also offered its highly efficient digital publishing platform to societies who wanted to try to make their journals OA and fund them through the APC model sharing a portion of the APC with BMC. 
BMC succeeded and eventually became profitable but the journey was anything but smooth. Tracz and Velterop seriously underestimated the cost of operating BMC despite developing a highly efficient system for managing peer-review and publication. They struggled for years, increasing the APCs while, at the same time, trying to increase submissions and reach the point where the company could be profitable. They nearly suffered an editorial revolt in the process but BMC did manage to reach profitability and in 2008 , was sold to Springer where it continues to be a successful OA publisher.

After leaving the NIH, Varmus went on to become President of Memorial Sloan-Kettering Cancer Center but retained his passion for opening up the scientific literature. He joined with Patrick Brown who had originally convinced him of the need for open access and another researcher, Michael Eisen to form the Public Library of Science (PLOS) in November 2000. ${ }^{17}$ Originally, PLOS was an advocacy organization aimed at creating a boycott of publishers who refused to make electronic copies of their articles freely available after six months of publication. Although they managed to get tens of thousands of signatures, the initiative flopped as most of the scientists who signed the pledge went right on publishing their manuscripts in the journals that they pledged to boycott. Taking the moral high road apparently gets a little tough when you are vying for tenure and promotion.

Undeterred, the three secured funding in 2003 from the Gordon and Betty Moore Foundation and reorganized PLoS into a non-profit academic publisher. ${ }^{19}$ Armed with about nine million USD to get the ball rolling, they used an APC model as a means of making PLoS sustainable but took a somewhat different tact than BMC. PLoS created a few very high-end journals that attempted to be on par with the best bioscience subscription journals in the world. They achieved their goal of creating top-tier journals. However, while charging much higher APCs, PLoS, like BMC, struggled to reach financial stability. The cost of high quality professional editing coupled with the low acceptance rates necessary for creating top tier journals made it very difficult to cover costs even with a high APC.

Towards the end of 2006, PLoS tried a different approach adding a new innovative journal called PLoS One to their portfolio. PLoS One was very broad in scope, covering all of biomedicine and related areas and following a peer-reviewed process with the narrow goal of ensuring that the research meet basic scientific and ethical quality standards without regard for the "importance" of the research presented in a manuscript. Manuscripts were to be reviewed and published quickly and PLoS provided a range of innovative tools allowing readers to comment directly in published articles and gain easy access to a variety of external measures of the impact of the papers published. The idea was to let the readers decide which articles in PLoS One were worth reading rather than having a set of reviewers make the decision for them. PLoS One eventually caught on in a big way, publishing over a 2,000 articles a month by mid-2012. Even with a modest APC, PLoS One was huge financial success and brought PLoS as a whole into profitability.

BMC and PLoS demonstrated that an APC funding model can work for OA scholarly publishing and since the launch of these two pioneering publishers, dozens and perhaps hundreds of professional publishers have launched publications based on the model. APCs not only provide a sustainable economic model 
for professional quality OA publishing, it changes the fundamental relationship among authors, publishers and readers or in reality their surrogates, libraries. Authors, rather than readers, become the financial customers of publishers. While in some sense publishers market their services to authors and readers with subscription and the APC models, the economic aspect of the equation flips with the APCs to authors being the purchasing agent, ultimately adding a new factor for authors to consider when choosing a journal in which to publish.

Professional OA publishing based on APCs appears, at this point, to become the dominate mode of open access publishing. The articles in APC-funded OA journals have been increasing at a faster rate than the articles published in journals funded by other means and currently account for about $49 \%$ of the total estimated 340,000 fully OA articles published in $2011^{20}$ while accounting for $27 \%$ of the journals listed in the Directory of Open Access Journals. ${ }^{21}$ APC-funded OA articles tend to be cited significantly more than other OA articles and, in the case of journals launched after 2002, are cited approximately as often their subscription counterparts. ${ }^{22}$

APC-funded OA does have a dark side. The nature of the economic model, along with the ease of setting up a website and claiming to be a publisher, has resulted in a substratum of pseudo-publishers who are incompetent and/or charlatans publishing virtually any manuscript that they are sent in order to collect an $\mathrm{APC}^{23}$. Fortunately, academics have tended to be savvy enough to largely avoid these low-end publishing sites while the legitimate professional OA publishers are attracting a growing number of submissions. As evidence of this, a reanalysis of data collected for another purpose ${ }^{24}$ showed that over two thirds of the articles published in OA journals charging APCs listed in the Directory of Open Access Publishers were in journals listed in the Web of Science which carefully screens journals before allowing them into the index.

A small segment of the OA articles published through APC funding are in, what are commonly known as, hybrid journals. Hybrid journals give authors the choice of making their individual articles OA in journals that are otherwise subscription. This model can be traced back to well before 2000 but was widely popularized by Springer's "Open Choice" program, started in 2004. The typical APC went up dramatically with Open Choice and since then, the uptake among authors publishing in hybrid journals has been very low, in the order of a few percent of the articles published in these journals. At this point, these data suggest this form of APC funded OA will ultimately be of little consequence. ${ }^{25}$

\section{Open Access Journals funded by means other than APCs}

While APC funded OA appears to be becoming the dominant force in scholarly publishing, most OA journals and about half the OA articles published are currently funded by other means, indicating that multiple options are likely to remain a vibrant and innovative part of OA publishing. A few universities, often through their libraries, have set up publishing services for their affiliated faculty. Two wellknown examples include the Scholarly Publishing Office at the University of Michigan and Igitur at Utrecht University. They provide the technical support and publishing platforms as well as collaborating with faculty to publish what are essentially professional quality OA journals such as Liber Quarterly, the 
journal of the Association of European Research Libraries published by Igitur and the Journal of Electronic Publishing published by the Scholarly Publishing Office.

There are also national and international publishing efforts that make digital versions of hundreds of journals, often published by societies, freely available on line. A good example is SciELO which is a multinational effort that publishes about 40,000 articles a year from around 900 journals, primarily from Latin America. Perhaps the largest sources of OA articles not funded by APCs are in journals that are published by societies distributing at least the digital versions of their journals at no charge. Caroline Sutton and Peter Suber have identified over 700 society journals that make their content freely available under a variety of open access licenses. ${ }^{26}$

In summary, OA journal articles made freely available upon publication have been increasing at a rate of about $30 \%$ a year and, as of 2009 , made and up roughly $8 \%$ of all peer-reviewed journal articles published. OA is still a small segment of scholarly publishing but if the rate of growth continues at this pace compared with an estimated 3.5\% annual growth rate for subscription publishing ${ }^{27}$, OA journal articles will become a significant portion of the total number of scholarly articles published within a few years.

\section{Open Access to Subscription Journals (Green Open Access)}

Another form of OA involves authors or, in some cases, publishers, placing versions of articles published in subscription journals in freely accessible archives, often affiliated with an institution of higher education. The form of open access is often termed "green" OA as opposed to OA journals which are termed "gold" OA. Björk and colleagues estimate these archived versions of subscription articles provide access to roughly $12 \%$ of the peer-reviewed published literature or nearly $50 \%$ more than OA journals. $^{28}$

Currently, the majority of subscription publishers allow authors to archive some form of their manuscripts, most commonly on the author's personal web site or a repository at their institution. Generally, authors are allowed to disseminate the final accepted version of their published articles, in some cases, with a delay. A growing number of academic institutions are providing repositories and, less commonly, a mandate for their employees to deposit a copy of their published articles in the institutional repository. Along with institutional repositories, there are also discipline-based repositories. A growing number of grantors are requiring their grantees to deposit copies of their published articles, derived from the research funded by their grants in repositories if not published in an OA journal. Probably the best known of the discipline-based repositories is PubMed Central, the legacy of Varmus's E-biomed proposal and the NIH requires that articles based on the research it funds be deposited in PubMed Central within a year of publication.

A related form of OA publishing is delayed access where publishers make the content of subscription journals freely available after a specific period of time, usually 6 months to one year after publication. 
These, again, tend to be professional society journals. Björk and colleagues estimated that approximately $3.5 \%$ of the scholarly literature was made available via delayed open access in $2006 .{ }^{29}$

\title{
Looking back after 20 years
}

\author{
"How will scholarly publishing evolve? The history of other technological innovations suggests \\ the shift to electronic publications will be rapid, but fundamental changes in the nature of \\ scholarly communications will be much slower." Andrew Odlyzko ${ }^{30}$
}

As Odlyzko predicted, the shift to digital distribution happened quickly. The tipping point, by a key measure, pricing model, occurred within less than a decade with librarians in large numbers requesting to purchase the digital versions of journals rather than the paper versions. ${ }^{31}$ Likewise, after 20 years, the structure of scholarly journals has not changed appreciably. As in the past, social dynamics, economic forces and the inertia of old habits are shaping the new digital scholarly publication system and, of course, it is not happening in a vacuum.

Clearly, scholarly publishing is in flux and the transition to a stable completely digital system is still a long way off. As noted by Schaffner, it is helpful to use the roles that journals play in scholarly communities as a lens to make sense of the transition to digital distribution. With the flexibility and efficiency provided by this new form of publication, there are a whole variety of models for fulfilling the traditional roles that journals have played in scholarly societies. Some, like Ginsparg's arXiv ${ }^{13}$, are not peerreviewed but perhaps fulfill the need for scholars to communicate among themselves more effectively than peer-reviewed journal articles. Ironically, as noted by John Willinsky ${ }^{3}$, the letters used by the natural philosophers to disseminate their research, copied and redistributed by early societies in the $17^{\text {th }}$ and $18^{\text {th }}$ century, were also seen as better fitting this role than the journals that slowly replaced them. Also, while arXiv is widely used, after digesting what they learned from the feedback via arXiv, physicists generally go on to publish their work in peer-reviewed journals.

The increasingly popular "mega journals," such as PLoS One, sit somewhat in between arXiv's nimble "scholarly skywriting" ${ }^{32}$ and the far more stilted but finely crafted traditional peer-reviewed journals. The narrowly focused peer-review process used by mega journals helps ensure scientific rigor and the ethical conduct of the research but little else. This facilitates quick and efficient publication, better fulfilling the communication role of journals but perhaps not as well as an arXiv-style repository. Mega journals provide standard professional publication practices such as permanent archiving and assigning DOls which are needed to fulfill the role of properly maintaining the scientific record albeit without profession editing and filtering for perceived importance. Authors receive credit for their work but generally not quite as much as in top-tier traditional journals. The scientific record is maintained but perhaps with not the same clarity. In essence, something is lost and something is gained.

Green OA provides a "having your cake and eating it too" economic approach to OA. At this point, it does not appear to be hurting subscription publishing. The subscription version maintains the scholarly record, assigns the appropriate credit to the authors and provides a professionally published version for 
those with access to it. The green archived version facilitates dissemination to those without access to the subscription version although the impact of this access is not clear and not perceived to be of much value by university faculty in the limited research to date on the topic. ${ }^{33}$ The uptake of green OA has been spotty, even with an increasing number of repositories and mandates by institutions and funders. It is not clear what impact this form of OA will have in the future. If the rate of green archiving increases, it may result in library subscriptions being cancelled which could eventually affect the bottom line of the publishers. Whether publishers would continue to allow green archiving or whether they will even be in a position to stop it is not clear at this point.

Digital distribution has opened up the possibility for a whole variety of economic models for scholarly publishing, some paying for access, some paying for publication and some paying for publishing as a service that is available to authors and readers without a direct charge. All are in play at the present time each with its own advantages and disadvantages. Currently it is not clear which if any will dominate in the future. In addition, new funding models for OA publication are still evolving with innovations such as the widely discussed PeerJ. ${ }^{34}$ Whether its membership funding model will prove viable remains to be seen but may provide another avenue for funding publication.

It seems pretty clear that some form of OA publishing will prevail. It enjoys broad-based support and it is easy to sell politically. The commercial publishers continue to lobby against OA publishing but they are also hedging their bets, experimenting with various author pay models to maintain a viable business in a changing world. At the same time, billions of dollars are tied up in subscription fees and library budgets are stretched to the limit. This is going to make the transition to an author pay or publishing service model a real challenge to implement, particularly for disciplines with little external funding. The process will be slow and painful and, in all likelihood, any major change in the economics of scholarly publishing is going to take several more decades to fully implement.

As in any transition to a new technology, much is gained but something is always lost. As Burbules and Bruce noted 17 years ago:

On the other hand, the care and precision of proofreading, revision, editing, designing, and typesetting manuscripts to create an authoritative (and aesthetically appealing) version of an author or authors' document has traditionally been linked with the finality of creating a printed, bound version that will be archived as such for posterity. Both the producer of the text and its editor and publisher have a common interest in seeing it be as complete, persuasive, and carefully written as possible, since there is a sense in which, once published, there is no taking it back. The printed medium, therefore, also has distinct benefits. ${ }^{35}$ (bolding added)

Burbules and Bruce's words ring true. High quality editing can still be found in journals but is getting less common, despite the fact that journal prices continue to rise. Some have attributed the loss to the economics of OA publishing ${ }^{36}$ but I feel Burbules and Bruce are closer to the truth; it is something deeper that is tied to the media itself. This, of course, begs the question of necessity. Few would argue 
with the need for care and precision in research and scholarship but is there the same need for care and precision in the writing and presentation? There is also the issue of whether carelessness in presentation will carry over in the other direction.

There is also something different in the journals themselves. While many journals, both subscription and $\mathrm{OA}$, have ties to professional societies, the numbers are dwindling and, along with them, the editorials, letters to the editor, announcements and eulogies that have marked journals as a key part of the social fabric that helps bind scholarly communities together. The extent to which journals will fulfill this role in the future remains to be seen.

It took hundreds of years to develop a finely honed paper journal system. In a mere 20 years, digitally distributed journals are still evolving and have a long way to go in working out the format, conventions, and economics that will allow the use of this new media to be as effective and as efficient as the paper media that they are replacing. As Odlyzko noted, while the transition to digital distribution is occurring very quickly, scholarly journals are currently making meager use of the true potential of what digital media has to offer in facilitating communication. Digital versions largely remain mirror images of their paper counterparts. In part, this is because their counterparts often still exist, shackling the digital version with their limitations. But it is deeper than that. Innovations to the structure of scholarly journals, such as open peer-review, have failed miserably ${ }^{37}$ as have the extensive and well-designed tools for annotating and commenting that were introduced in journals such as those in PLoS One. It is also rare see the use of multimedia, web 2.0 style interactive tools or for authors to share their data though the technology for implementing each of these innovations is readily available. ${ }^{38}$ While the efficiency and ease of access provided by digital distribution was quickly adopted, there appears to be little interest, at this point in time, in what else it has to offer. Perhaps, as with the development of the journal format 350 years ago, it will not be the availability of technology but a fundamental change in science and scholarship itself that will bring about next real change in scholarly communication. 


\section{Notes and References}

\footnotetext{
${ }^{1}$ I use the term digitally distributed journals rather than digital journals since the key issue is the distribution of the journal in digital form.

${ }^{2}$ Schaffner Ann C. The Future of Scientific Journals: Lessons from the Past. Information Technology and Libraries, v13 n4 p239-47 Dec 1994.

${ }^{3}$ Willinsky J. The Access Principle. The Case for Open Access to Research and Scholarship The MIT Press, 2005.

${ }^{4}$ Guédon J. 2001. "In Oldenburg's long shadow: Librarians, research scientists, publishers, and the control of scientific publishing," Presentation to the May 2001 meeting of the Association of Research Libraries (ARL), Available: http://www.arl.org/resources/pubs/mmproceedings/138guedon.shtml Accessed 2012-09-14

${ }^{5}$ Kronick DA. Peer Review in 18th-Century Scientific Journalism. JAMA March 9, 1990 263;10:1321-2.

${ }^{6}$ Burnham JC. The evolution of editorial peer review. JAMA March 9, 1990 263;10:1323-22.

${ }^{7}$ Throughout this paper I have used scholars broadly to refer to those individuals who both author and largely read scholarly journal articles.

${ }^{8}$ ARL web site. http://www.arl.org/sc/marketplace/journals/index.shtml

${ }^{9}$ Crow R. Publishing cooperatives: An alternative for non-profit publishers. First Monday, volume 11, number 9 (September 2006), URL: http://firstmonday.org/issues/issue11 9/crow/index.html
}

${ }^{10}$ Parang, E. Sanders L. 1994. Electronic Journals in ARL Libraries: Policies \& Procedures. SPEC Kit 201. Washington, D.C.: Association of Research Libraries, Office of Management Service. Available:

http://www.webcitation.org/5LrbLKI6Y Accessed 2012-09-14

${ }^{11}$ Estes WK. Electronic Publishing: A Scorecard and an Agenda. Psychological Science, Vol. 1, No. 6 Nov., 1990), pp. 360-361.

${ }^{12}$ Education Policy Analysis Archives Available: http://epaa.asu.edu/ojs/ Accessed 2012-09-14

${ }^{13}$ Ginsparg P. Creating a global knowledge network. Invited contribution for Conference held at UNESCO HQ, Paris, 19-23 Feb 2001, Second Joint ICSU. Press Available: http://people.ccmr.cornell.edu/ ginsparg/blurb/pg01unesco.html Accessed 2012-09-14

${ }^{14}$ Original Proposal for E-biomed (Draft and Addendum) E-BIOMED: A Proposal for Electronic Publications in the Biomedical Sciences http://www.nih.gov/about/director/pubmedcentral/ebiomedarch.htm Accessed 2012-09-14

${ }^{15}$ Second paragraph of the section "A proposal for E-biomed".

${ }^{16}$ For example see http://www.nih.gov/about/director/ebiomed/com0509.htm Unfortunately the index appears to no longer be on the NIH server.

${ }^{17}$ Poynder R. Open and Shut? Interview with Harold Varmus. 2006-06-05. Available : http://poynder.blogspot.com/2006/06/interview-with-harold-varmus.html. Accessed 2012-09-14

18 Poynder R. Open and Shut? Interview with Vitek Tracz. 2006-05-23. Available:

http://poynder.blogspot.com/2006/05/interview-with-vitek-tracz.html. Accessed 2012-09-14 
${ }^{19}$ Open Access Timeline 2000, The Open Access Directory Available at http://oad.simmons.edu/oadwiki/Timeline 2000.

${ }^{20}$ Personal communication with Bo-Christer Björk and Mikael Laakso based on as yet unpublished research.

${ }^{21}$ Based on data downloaded from the DOAJ site on August 7,2012.

${ }^{22}$ Björk B-C and Solomon DJ. Open access versus subscription journals: a comparison of scientific impact BMC Medicine 2012, 10:73 http://www.biomedcentral.com/1741-7015/10/73 doi:10.1186/1741-7015-10-73

${ }^{23}$ Elliott C. On Predatory Publishers: a Q\&A With Jeffrey Beall. The Chronicle of Higher Education June 52012.

${ }^{24}$ Solomon DJ, Björk B-C. A Study of Open Access Journals Using Article Processing Charges. Journal of the American Society for Information Science and Technology 63(8):1485-1495, 2012 10.1002/asi.22673.

${ }^{25}$ Björk B-C. The Hybrid Model for Open Access Publication of Scholarly Articles: A Failed Experiment? Journal of the American Society for Information Science and Technology 63(8):1496-1504, 2012 10.1002/asi.22709.

${ }^{26}$ A spreadsheet with information about the journals can be found here (http://bit.ly/oaj-society).

${ }^{27}$ Laakso M, Welling P, Bukvova H, Nyman L, Björk B-C, et al. (2011) The Development of Open Access Journal Publishing from 1993 to 2009. PLoS ONE 6(6): e20961. doi:10.1371/journal.pone.0020961.

${ }^{28}$ Björk B-C, Welling P, Laakso M, Majlender P, Hedlund T, et al. (2010) Open Access to the Scientific Journal Literature: Situation 2009. PLoS ONE 5(6): e11273. doi:10.1371/journal.pone.0011273.

${ }^{29}$ Björk, B-C., Roos, A. \& Lauri, M. (2009). "Scientific journal publishing: yearly volume and open access availability" Information Research, 14(1) paper 391. [Available from 12 January, 2009 at http://InformationR.net/ir/141/paper391.html]

${ }^{30}$ Odlyzko A. The slow evolution of electronic publishing. Preliminary version. September 20, 1997. http://www.dtc.umn.edu/ odlyzko/doc/slow.evolution.pdf (Abstract, Accessed 06-17-2012)

${ }^{31}$ L. Van Orsdel and K. Born, 2002. "Periodicals Price Survey 2002: Doing the Digital Flip," Library Journal, http://www.libraryjournal.com/article/CA206383.html. (Accessed 07-17-2012)

${ }^{32}$ Harnad S. Scholarly Skywriting and the Prepublication Continuum of Scientific Inquiry Psychological Science, Vol. 1, No. 6 (Nov., 1990), pp. 342-344.

${ }^{33}$ Davis PM, Walters WH. The impact of free access to the scientific literature: a review of the recent research. Journal of the Medical Library Association 99(3) July 2011 208-217.

${ }^{34}$ PeerJ https://peeri.com/ Accessed 2012-09-14

${ }^{35}$ Burbules NC, Bruce BC. This is not a paper Educational Researcher 1995;24(8):12-8. (quote 15-16)

${ }^{36}$ For example http://scholarlykitchen.sspnet.org/2012/07/26/review-and-discussion-free-ride-how-digitalparasites-are-destroying-the-culture-business-and-how-the-culture-business-can-fight-back/. 
${ }^{37}$ Overview: Nature's peer review trial. Despite enthusiasm for the concept, open peer review was not widely popular, either among authors or by scientists invited to comment. Nature (2006) doi:10.1038/nature05535

${ }^{38}$ Mascarelli AL Data's shameful neglect. Nature 461, 145 (10 September 2009) doi:10.1038/461145 